Ciptaan disebarluaskan di bawah

Lisensi Creative Commons

Atribusi-NonKomersial-BerbagiSerupa 4.0

\title{
FAKTOR-FAKTOR YANG BERHUBUNGAN DENGAN KEPATUHAN \\ MELAKUKAN PENGOBATAN SECARA TERATUR PADA \\ PENDERITA HIPERTENSI USIA PRODUKTIF DI \\ PUSKESMAS HANTARA KABUPATEN \\ KUNINGAN 2020
}

Asikin, Dewi Laelatul Badriah, Rossi Suparman, Susianto

STIKes Kuningan

drasikin92@gmail.com

\begin{abstract}
Abstrak
Prevalensi penyakit hipertensi di Jawa Barat sebesar 39,6\%. Angka tersebut melebihi angka nasional yang hanya 34,11\%. Kabupaten Kuningan memiliki prevalensi penyakit hipertensi yang cukup tinggi. Dari total laki-laki dan perempuan yang berusia produktif, terdapat $15,06 \%$ orang yang memiliki penyakit hipertensi dan hanya sebesar 38,33\% yang memiliki kepatuhan melakukan pengobatan secara teratur. Tujuan penelitian ini untuk menganalisis faktor-faktor yang berhubungan dengan kepatuhan pengobatan teratur pada penderita hipertensi usia produktif di Puskesmas Hantara Kabupaten Kuningan 2020. Jenis penelitian ini observasional analitik dengan desain cross sectional (potong lintang). Populasi penelitian ini berjumlah 861 orang dan pengambilan sampel dengan menggunakan teknik disproportionate stratified random sampling sebanyak 273 responden. Instrumen penelitian ini menggunakan sfigmomanometer, stetoskop dan lembar kuesioner tertutup. Sumber data penelitian ini adalah data primer dan sekunder. Analisis data meliputi analisis univariat, analisis bivariat Uji Korelasi Rank Spearman.

Distribusi perilaku kepatuhan responden dalam melakukan pengobatan hipertensi secara teratur didapatkan hasil sebanyak 109 orang $(39,9 \%)$ diantaranya memiliki perilaku tidak patuh dalam melakukan pengobatan hipertensi secara teratur, sedangkan 164 orang $(60,1 \%)$ lainnya memiliki perilaku patuh dalam melakukan pengobatan hipertensi secara teratur. Hasil uji korelasi Rank Spearman, terdapat hubungan yang bermakna antara tingkat pengetahuan $(p=0,000)$, tingkat pendidikan $(p=0,001)$, penghasilan $(p=0,001)$ dan jarak rumah responden ke Puskesmas $(\mathrm{p}=0,010)$ dengan kepatuhan dalam melakukan pengobatan hipertensi secara teratur. Terdapat hubungan antara tingkat pengetahuan, tingkat pendidikan, penghasilan dan jarak rumah responden ke Puskesmas dengan kepatuhan dalam melakukan
\end{abstract}


JOURNAL OF PUBLIC HEALTH INOVATION

VOL. 2 NO. 01, DESEMBER 2021

DOI: $10.34305 / j p h i . v 2 i 1.330$
Ciptaan disebarluaskan di bawah

Lisensi Creative Commons

Atribusi-NonKomersial-BerbagiSerupa 4.0

pengobatan hipertensi secara teratur di Wilayah Kerja UPTD Puskesmas Hantara Kabupaten Kuningan tahun 2020. Diharapkan penderita hipertensi agar teratur melakukan kontrol tekanan darah sesuai dengan anjuran dokter sehingga dapat meminimalisir terjadinya kemungkinan komplikasi.

Kata Kunci : Hipertensi, Pengetahuan, Pendidikan, Penghasilan, Jarak, Kepatuhan

\section{Pendahuluan}

Kesehatan merupakan suatu hal yang penting dan harus dimiliki oleh seseorang, karena apabila seseorang itu sehat maka dia dapat menjalankan kehidupannya secara produktif. Permasalahan kesehatan di Indonesia masih ditandai dengan tingginya angka kesakitan dan kematian akibat penyakit tidak menular. Salah satu penyakit tidak menular yang hingga saat ini masih belum dapat diatasi sepenuhnya adalah penyakit hipertensi, sekalipun pemerintah melalui Kementerian Kesehatan telah menetapkan berbagai program untuk menekan angka insidensi penyakit hipertensi (Entianopa et al., 2017).

Penyakit tidak menular (PTM) merupakan penyebab kematian hampir 70\% di dunia. PTM merupakan penyakit kronis yang tidak ditularkan dari orang ke orang. PTM diantaranya adalah penyakit jantung, stroke, kanker, diabetes, Penyakit Paru
Obstruktif Kronis (PPOK) dan hipertensi. PTM menunjukkan adanya kecenderungan semakin meningkat dari waktu ke waktu. World Health Organization (WHO) pada 2020 menyebutkan bahwa jumlah penderita hipertensi akan terus meningkat seiring dengan jumlah penduduk yang terus bertambah. Diperkirakan pada 2025 mendatang akan ada sekitar (29\%) warga dunia yang terkena hipertensi. WHO menyebutkan bahwa negara berkembang memiliki sekitar (40\%) penduduknya menderita penyakit hipertensi, sedangkan negara maju hanya sekitar (35\%) penduduknya menderita penyakit hipertensi. Di kawasan Asia, penyakit hipertensi ini telah membunuh 1,5 juta orang setiap tahunnya (Jankowska-Polańska et al., 2016).

Hasil (Riskesdas, 2007); (Riskesdas, 2013); (Riskesdas, 2018) tampak kecenderungan peningkatan prevalensi PTM seperti diabetes, hipertensi, stroke, 
JOURNAL OF PUBLIC HEALTH INOVATION

VOL. 2 No. 01, DESEMBER 2021

DOI: $10.34305 / j p h i . v 2 i 1.330$
Ciptaan disebarluaskan di bawah

Lisensi Creative Commons

Atribusi-NonKomersial-BerbagiSerupa 4.0 dan penyakit sendi/rematik/encok. Fenomena ini diprediksi akan terus berlanjut (Nugraha, 2018). Hasil (Riskesdas, 2018) menunjukkan bahwa prevalensi penduduk Indonesia dengan hipertensi sebesar (34,11\%). Prevalensi hipertensi pada perempuan sebesar (36,85\%) lebih tinggi dibanding dengan laki-laki dengan persentase $(31,34 \%)$. Lalu prevalensi di perkotaan sedikit lebih tinggi yaitu sebesar $(34,43 \%)$ dibandingkan dengan pedesaan yang hanya $(33,72 \%)$. Prevalensi hipertensi semakin meningkat seiring dengan pertambahan umur.

Berdasarkan (Dinas Kesehatan Jawa Barat, 2020), prevalensi penyakit hipertensi di Jawa Barat sebesar 39,6\%. Angka tersebut melebihi angka nasional yaitu sebesar 34,11\%. Prevalensi penyakit hipertensi di Jawa Barat berada pada posisi kedua tertinggi di Indonesia setelah provinsi Kalimantan Selatan. Hal tersebut dipengaruhi oleh beberapa faktor, seperti: usia, keturunan, obesitas, kurangnya aktivitas fisik dan olahraga, serta kebiasaan merokok. Selain itu, berdasarkan rekapitulasi Indeks Keluarga Sehat angka capaian penderita hipertensi yang berobat teratur tingkat di Provinsi Jawa Barat 2018 sebesar $(26,19 \%)$ dan pada 2019 meningkat menjadi (31,17\%) (Pujiyanto, 2008).
Kabupaten Kuningan merupakan salah satu kabupaten di Jawa Barat yang memiliki luas 1.195,71 km2 dengan total 32 kecamatan (BPS Kabupaten Kuningan, 2019). Kabupaten Kuningan memiliki prevalensi penyakit hipertensi yang cukup tinggi. Dari total laki-laki dan perempuan yang berusia $\geq 18$ tahun yang dilakukan pengukuran tekanan darah sebanyak 436.659 orang, terdapat $65.761(15,06 \%)$ orang yang memiliki penyakit hipertensi. Kabupaten Kuningan memiliki angka kepatuhan penderita hipertensi yang berobat secara teratur pada 2018 sebesar $(31,17 \%)$ kemudian meningkat pada 2019 menjadi (31,83\%) (Dinas Kesehatan Kabupaten Kuningan, 2020). Meskipun angka kepatuhan berobat secara teratur meningkat, angka tersebut masih masuk ke dalam kategori rendah, dikarenakan menurut Peraturan Menteri Kesehatan Republik Indonesia Nomor 4 Tahun 2019, standar nasional untuk angka kepatuhan dalam berobat untuk penderita hipertensi di setiap daerah untuk kategori tinggi adalah $\geq 75 \%$.

Demikian pula prevalensi hipertensi di Puskesmas Hantara dari tahun ke tahun semakin meningkat. Berdasarkan data dari Laporan Puskesmas Hantara 2019 terdapat 1.768 orang penambahan kasus baru hipertensi. Kemudian pada 2020 terdapat 
JOURNAL OF PUBLIC HEALTH INOVATION

VOL. 2 NO. 01, DESEMBER 2021

DOI: $10.34305 / j p h i . v 2 i 1.330$
Ciptaan disebarluaskan di bawah

Lisensi Creative Commons

Atribusi-NonKomersial-BerbagiSerupa 4.0 penambahan kasus baru hipertensi di Puskesmas Hantara sebanyak 1.336 orang. Namun, penambahan kasus baru hipertensi tidak disertai dengan peningkatan kepatuhan pengobatan secara teratur oleh penderita hipertensi, dikarenakan angka kepatuhan pengobatan secara teratur di Puskesmas Hantara sangatlah rendah. Angka capaian penderita hipertensi yang berobat teratur pada 2018 hanya sebesar $(38,15 \%)$ kemudian sebesar $(38,33 \%)$ pada tahun 2019. Banyak faktor yang diduga berhubungan dengan rendahnya kepatuhan penderita hipertensi pada usia produktif untuk berobat teratur di Puskesmas Hantara. Faktor tersebut dapat bersifat karena internal pribadi penderita hipertensi maupun adanya faktor eksternal yang mempengaruhinya. Faktor internal yang mempengaruhi rendahnya kepatuhan penderita hipertensi pada usia produktif seperti umur, jenis kelamin, pendidikan, pengetahuan, penghasilan dan lama mengkonsumsi obat hipertensi. Sedangkan faktor eksternal yang mempengaruhi rendahnya kepatuhan penderita hipertensi pada usia produktif seperti peran keluarga, peran petugas Puskesmas dan jarak rumah penderita ke fasilitas pelayanan kesehatan.

Penderita hipertensi melakukan pengobatan secara teratur termasuk kedalam 12 indikator PIS PK (Program Indonesia Sehat dengan Pendekatan Keluarga) yang menjadi permasalahan utama di Puskesmas Hantara Kabupaten Kuningan dikarenakan angka kepatuhan penderita hipertensi yang berobat secara teratur sangatlah rendah yaitu berada di angka (31,83\%), masih jauh dari standar nasional yaitu sebesar $\geq 75 \%$ untuk masuk kedalam kategori tinggi. Oleh karena itu, penting untuk ditelusuri kemungkinan keterlibatan berbagai faktor yang berhubungan dengan rendahnya angka kepatuhan berobat secara teratur pada penderita hipertensi di Puskesmas Hantara Kabupaten Kuningan 2020.

Situasi dan kondisi tersebut membuat peneliti tertarik untuk mengkaji faktor-faktor yang berhubungan dengan kepatuhan melakukan pengobatan secara teratur pada penderita hipertensi usia produktif di Puskesmas Hantara Kabupaten Kuningan 2020.

\section{Metode}

Penelitian ini menggunakan jenis penelitian observasional analitik. Adapun desain rancangan yang digunakan dalam penelitian ini adalah cross sectional (potong lintang). Tujuan dari penelitian ini adalah untuk mengamati faktor-faktor yang 
JOURNAL OF PUBLIC HEALTH INOVATION

VOL. 2 No. 01, DESEMBER 2021

DOI: $10.34305 / j p h i . v 2 i 1.330$
Ciptaan disebarluaskan di bawah

Lisensi Creative Commons

Atribusi-NonKomersial-BerbagiSerupa 4.0 berhubungan dengan kepatuhan melakukan pengobatan secara teratur pada penderita hipertensi usia produktif di Puskesmas Hantara Kabupaten Kuningan tahun 2020.

Variabel independen dalam penelitian ini yaitu pengetahuan, pendidikan, penghasilan dan jarak rumah penderita ke Puskesmas. Sedangkan Variabel dependen dalam penelitian ini adalah kepatuhan pengobatan secara teratur pada penderita hipertensi usia produktif. Adapun populasi dalam penelitian ini adalah seluruh penderita hipertensi dari usia produktif ( $\geq 15$ tahun dan $<60$ tahun) yang berobat ke Puskesmas Hantara Kabupaten Kuningan tahun 2020 dengan jumlah 861 orang dan pengambilan sampel penelitian dengan menggunakan teknik disproportionate stratified random sampling didapatkan hasil bahwa sampel penelitian sebanyak 273 responden.

Instrumen yang digunakan dalam penelitian ini menggunakan alat sfigmomanometer dan stetoskop untuk pemeriksaan tekanan darah responden. Dan juga menggunakan lembar kuesioner tertutup. Sumber data yang digunakan dalam penelitian ini adalah data primer dan sekunder. Data primer diperoleh dari hasil pengisian lembar kuesioner kepada penderita hipertensi usia produktif sebanyak 273 orang yang berasal dari 8 desa yang termasuk wilayah kerja Puskesmas Hantara Kabupaten Kuningan tahun 2020. Sedangkan data sekundernya berasal dari pemegang program PTM, data laporan tahunan puskesmas Hantara dan Dinas Kesehatan Kabupaten Kuningan yang berkaitan dengan penyakit hipertensi.

Analisis data dalam penelitian ini meliputi analisis univariat, analisis bivariat dengan menggunakan Uji Korelasi Rank Spearman. Penelitian ini dilaksanakan pada tanggal 28 Desember 2020 - 29 Januari 2021. Selanjutnya akan dibahas dengan mengemukakan hasil penelitian dan menghubungkan dengan hipotesis yang telah dibuat.

\section{Hasil}

Berdasarkan Tabel 1, gambaran variabel bebas yang diteliti dalam penelitian ini adalah mayoritas memiliki pengetahuan yang baik sebanyak 112 orang (41\%), distribusi tingkat Pendidikan kebanyakan lulusan SD sebanyak 151 orang (55,3\%). Untuk penghasilan responden per-bulan mayoritas kurang dari Rp. 1.882 .642 perbulan yaitu sebanyak 239 orang (87,5\%). Untuk jarak rumah ke pelayanan Kesehatan mayoritas memiliki jarak yang dekat yaitu sebanyak 180 orang $(65,9 \%)$. 
JOURNAL OF PUBLIC HEALTH INOVATION

VOL. 2 NO. 01, DESEMBER 2021

DOI: $10.34305 /$ jphi.v2i1.330
Ciptaan disebarluaskan di bawah

Lisensi Creative Commons Atribusi-NonKomersial-BerbagiSerupa 4.0 Internasional

Kemudian untuk distribusi perilaku hipertensi secara teratur kebanyakan sudah kepatuhan dalam melakukan pengobatan patuh yaitu sebanyak 164 orang $(60,1 \%)$.

Tabel 1. Analisis Univariat

\begin{tabular}{|c|c|c|}
\hline Variabel & Jumlah & Persentase \\
\hline \multicolumn{3}{|l|}{ Tingkat Pengetahuan } \\
\hline - Kurang & 51 & 18,7 \\
\hline - Cukup & 110 & 40,3 \\
\hline - $\quad$ Baik & 112 & 41 \\
\hline \multicolumn{3}{|l|}{ Tingkat Pendidikan } \\
\hline$-\mathrm{SD}$ & 151 & 55,3 \\
\hline - SMP & 72 & 26,4 \\
\hline - SMA & 50 & 18,3 \\
\hline \multicolumn{3}{|l|}{ Penghasilan } \\
\hline - $\quad$ Kurang Dari Rp. 1.882.642 Per-Bulan > & 239 & 87,5 \\
\hline - $\quad$ Lebih Dari Rp. 1.882.642 Per-Bulan & 34 & 12,5 \\
\hline \multicolumn{3}{|l|}{ Jarak Ke Fasyankes } \\
\hline - Jarak Dekat & 180 & 65,9 \\
\hline - Jarak Jauh & 93 & 34,1 \\
\hline \multicolumn{3}{|l|}{ Perilaku Kepatuhan } \\
\hline - Tidak Patuh & 109 & 39,9 \\
\hline - Patuh & 164 & 60,1 \\
\hline TOTAL & 273 & 100 \\
\hline
\end{tabular}

(Sumber : Penelitian Tahun 2021)

Tabel 2. Analisis Bivariat Pengaruh Faktor-Faktor Independen Terhadap Kejadian Preeklampsia

\begin{tabular}{|c|c|c|c|c|c|}
\hline \multirow[t]{2}{*}{ Variabel } & \multicolumn{2}{|c|}{$\begin{array}{c}\text { Kepatuhan Melakukan } \\
\text { Pengobatan Hipertensi secara } \\
\text { teratur }\end{array}$} & \multirow[t]{2}{*}{ Total } & \multirow[t]{2}{*}{ Nilai $p$} & \multirow[t]{2}{*}{ Koefisien Korelasi } \\
\hline & Tidak Patuh & Patuh & & & \\
\hline \multicolumn{6}{|l|}{ Tingkat Pengetahuan } \\
\hline - Kurang & $30(57,7)$ & $21(43,3)$ & 1 & & \\
\hline - Cukup & $49(41,9)$ & $61(58,1)$ & 10 & 0,000 & 0,216 \\
\hline - Baik & $36(31)$ & $76(69)$ & 112 & & \\
\hline \multicolumn{6}{|l|}{ Tingkat Pendidikan } \\
\hline$-\mathrm{SD}$ & $74(48,7)$ & $77(51,3)$ & 15 & & \\
\hline - SMP & $23(32,3)$ & $49(67,7)$ & 72 & 0,001 & 0,206 \\
\hline - SMA & $12(32,1)$ & $34(67,9)$ & 0 & & \\
\hline \multicolumn{6}{|l|}{ Tingkat Penghasilan } \\
\hline$<$ Rp.1.882.642 Bulan & $109(43,7)$ & $130(56,3)$ & 39 & 0,037 & 0,126 \\
\hline > Rp.1.882.642 Bulan & $12(40,5)$ & $22(59,5)$ & 4 & & \\
\hline \multicolumn{6}{|c|}{ Jarak Rumah Ke Puskesmas } \\
\hline - Jarak Jauh & $46(49,5)$ & $47(50,5)$ & 3 & 0,010 & 0,156 \\
\hline - Jarak Dekat & $62(34,4)$ & $118(65,6)$ & 80 & & \\
\hline
\end{tabular}

(Sumber :Penelitian tahun 2020) 
JOURNAL OF PUBLIC HEALTH INOVATION

VOL. 2 NO. 01, DESEMBER 2021

DOI: $10.34305 / j p h i . v 2 i 1.330$
Ciptaan disebarluaskan di bawah

Lisensi Creative Commons

Atribusi-NonKomersial-BerbagiSerupa 4.0
Berdasarkan tabel 2. Hasil analisis bivariat dengan uji korelasi Spearman Rank menunjukkan terdapat hubungan yang bermakna antara tingkat pengetahuan $(\mathrm{p}=$ $0,000)$, tingkat pendidikan $(\mathrm{p}=0,001)$, penghasilan $(\mathrm{p}=0,001)$ dan jarak rumah responden ke Puskesmas $(\mathrm{p}=0,010)$ dengan kepatuhan dalam melakukan pengobatan hipertensi secara teratur di Wilayah Kerja UPTD Puskesmas Hantara Kabupaten Kuningan tahun 2020.

\section{Pembahasan}

1. Korelasi Tingkat Pengetahuan Dengan Kepatuhan Dalam Melakukan Pengobatan Hipertensi Secara Teratur

Dari hasil analisis bivariat dengan melakukan uji korelasi Rank Spearman dengan nilai $\mathrm{p}=0,000$ atau $\mathrm{p}<0,05$ maka keduanya dinyatakan memiliki hubungan. Untuk koefisien korelasinya didapatkan nilai positif 0,216 baik untuk tingkat pengetahuan maupun kepatuhan dalam melakukan pengobatan hipertensi secara teratur yang berarti korelasinya lemah. Sehingga dapat disimpulkan bahwa semakin tinggi pengetahuan responden maka semakin tinggi pula kepatuhan responden dalam melakukan pengobatan hipertensi secara teratur.
Pengetahuan dapat diartikan sebagai kumpulan informasi yang dipahami, diperoleh dari proses belajar selama hidup dan dapat dipergunakan sewaktu-waktu sebagai alat penyesuaian diri, baik terhadap diri sendiri maupun lingkungan. Pengetahuan tentang suatu objek dapat diperoleh dari pengalaman guru, orang tua, teman, buku dan media massa. Dapat disimpulkan dari teori tersebut bahwa pengetahuan penderita hipertensi dapat menjadi guru yang baik bagi dirinya, dengan pengetahuan yang dimiliki akan mempengaruhi kepatuhan penderita hipertensi tersebut dalam menjalani pengobatan. Penderita yang mempunyai pengetahuan tinggi cenderung lebih patuh berobat daripada penderita yang berpengetahuan rendah (Notoatmodjo, 2012).

Hasil penelitian ini diperkuat oleh penelitian yang telah dilakukan (Rachmawati \& Ekarini, 2015) yang menunjukan bahwa ada hubungan antara pengetahuan dengan kepatuhan berobat pada pasien hipertensi dengan $(p=0,002)$. Dalam penelitianya Ekarini menyebutkan adanya hubungan antara pengetahuan dengan kepatuhan berobat ini dikarenakan adanya upaya yang telah dilakukan oleh petugas kesehatan diantaranya dengan 
JOURNAL OF PUBLIC HEALTH INOVATION

VOL. 2 NO. 01, DESEMBER 2021

DOI: $10.34305 / j p h i . v 2 i 1.330$
Ciptaan disebarluaskan di bawah

Lisensi Creative Commons

Atribusi-NonKomersial-BerbagiSerupa 4.0 mensosialisasikan pentingnya menjalani pengobatan yang teratur bagi klien hipertensi, penyuluhan kesehatan mengenai penyakit hipertensi, pemberian brosur tentang penyakit hipertensi. Hal ini secara tidak langsung mampu meningkatkan pengetahuan klien hipertensi sehingga memotivasi klien hipertensi untuk menjalani pengobatan secara teratur. Hal ini juga didukung oleh penelitian yang dilakukan (Rasajati et al., 2015) dan (Harahap et al., 2019), yang menunjukan masing-masing nilai $(\mathrm{p}=0,001)$ dan $(\mathrm{p}=$ 0,014). Dalam penelitian tersebut menjelaskan bahwa responden yang berpengetahuan tinggi maupun rendah sama-sama ingin sembuh dari penyakit sehingga tingkat pendidikan tidak mempengaruhi kepatuhan melakukan pengobatan.

Dalam hal lain berbeda dengan hasil penelitian yang dilakukan oleh (Ambaw et al., 2012) yang menunjukan bahwa pengetahuan tidak mempunyai pengaruh terhadap penggunaan obat antihipertensi. Hal ini dikarenakan penelitian tersebut termasuk dalam penelitian deskriptif yang dilihat dari rangkuman data yang ada. Penelitian ini adalah penelitian observasional analitik dimana diuji hingga tahap bivariat sehingga diketahui keeratan hubungan/ korelasi.

2. Korelasi Tingkat Pendidikan Dengan Kepatuhan Dalam Melakukan Pengobatan Hipertensi Secara Teratur Dari hasil analisis bivariat dengan melakukan uji korelasi Rank Spearman dengan nilai $\mathrm{p}=0,001$ atau $\mathrm{p}<0,05$ maka keduanya dinyatakan memiliki hubungan. Untuk koefisien korelasinya didapatkan nilai positif 0,206 baik untuk tingkat pendidikan maupun kepatuhan dalam melakukan pengobatan hipertensi secara teratur yang berarti korelasinya lemah. Sehingga dapat disimpulkan bahwa semakin tinggi pendidikan responden maka semakin tinggi pula kepatuhan responden dalam melakukan pengobatan hipertensi secara teratur.

Menurut teori Lawrence Green (1980) dalam (Notoatmodjo, 2014) menyatakan bahwa perilaku patuh dipengaruhi oleh faktor-faktor predisposisi, salah satunya pendidikan. Pendidikan adalah suatu kegiatan atau proses pembelajaran untuk mengembangkan atau meningkatkan kemampuan tertentu sehingga sasaran pendidikan itu dapat berdiri sendiri. Responden yang berpendidikan lebih tinggi akan mempunyai pengetahuan yang lebih luas dibandingkan 
JOURNAL OF PUBLIC HEALTH INOVATION

VOL. 2 NO. 01, DESEMBER 2021

DOI: $10.34305 / j p h i . v 2 i 1.330$
Ciptaan disebarluaskan di bawah

Lisensi Creative Commons

Atribusi-NonKomersial-BerbagiSerupa 4.0 dengan responden yang tingkat pendidikanya rendah. (Suwarso, 2010) juga menyatakan tingkat pendidikan dapat mempengaruhi kemampuan dan pengetahuan seseorang dalam menerapkan perilaku hidup sehat, terutama mencegah penyakit hipertensi. Semakin tinggi tingkat pendidikan maka akan semakin tinggi pula kemampuan seseorang dalam menjaga pola hidupnya agar tetap sehat.

Hasil penelitian ini diperkuat penelitian yang dilakukan oleh (Amran et al., 2010) yang menyatakan terdapat hubungan antara tingkat pendidikan dengan kepatuhan pengobatan hipertensi $(p=0,001)$. Hal ini dikarenakan pada hasil penelitian, dari total responden yang berpendidikan tinggi sebanyak $70,9 \%$ responden patuh menjalani pengobatan dan $29,1 \%$ responden tidak patuh menjalani pengobatan. Pada penelitian ini juga ditemukan bahwa responden dengan pendidikan SMA sebanyak 50 orang dan 37 orang diantaranya memiliki kepatuhan dibandingkan dengan responden yang berpendidikan SD sebanyak 151 dan 77 orang diantaranya memiliki perilaku tidak patuh dalam melakukan.

Berbeda dengan hasil penelitian ini, penelitian (Aris, 2007) menunjukan bahwa tidak terdapat hubungan antara tingkat pendidikan terhadap kepatuhan minum obat antihipertensi di Rumah sakit Kota Kiambu $(\mathrm{p}=0,191)$. Dalam penelitian Kimuyu distribusi tingkat pendidikan responden lebih heterogen jika dibandingkan pada penelitian ini yang cenderung mengelompok lebih besar pada responden berpendidikan dasar yaitu sebesar 55,3\% dari total responden sehingga hasil dapat berbeda.

Ketidakpatuhan pada responden dengan pendidikan rendah dapat disebabkan karena faktor minimnya pengetahuan yang mereka miliki, hal ini ditunjukan pada responden dengan pendidikan SD sebesar $55,3 \%$ memiliki pengetahuan yang rendah juga tentang penyakitnya. Pendidikan sangat erat kaitanya dengan pengetahuan, pendidikan merupakan proses belajar mengajar sehingga akan terbentuk seperangkat tingkah laku, kegiatan atau aktivitas. Dengan belajar baik secara formal maupun non formal manusia akan dapat meningkatkan kematangan intelektual dan memiliki pengetahuan. Dengan pengetahuan yang diperoleh maka pasien hipertensi akan mengetahui manfaat dari saran atau nasihat petugas kesehatan sehingga akan termotivasi untuk lebih patuh menjalani pengobatan yang dianjurkan oleh petugas kesehatan. 
JOURNAL OF PUBLIC HEALTH INOVATION

VOL. 2 No. 01, DESEMBER 2021

DOI: $10.34305 / j p h i . v 2 i 1.330$
Ciptaan disebarluaskan di bawah

Lisensi Creative Commons

Atribusi-NonKomersial-BerbagiSerupa 4.0
3. Korelasi Penghasilan Dengan Kepatuhan

Dalam Melakukan Pengobatan

Hipertensi Secara Teratur

Berdasarkan hasil analisis bivariat dengan melakukan uji korelasi Rank Spearman dengan nilai $p=0,037$ atau $p<$ 0,05 maka keduanya dinyatakan memiliki hubungan. Untuk koefisien korelasinya didapatkan nilai positif 0,126 baik untuk penghasilan maupun kepatuhan dalam melakukan pengobatan hipertensi secara teratur yang berarti korelasinya sangat lemah. Sehingga dapat disimpulkan bahwa semakin tinggi penghasilan responden maka semakin tinggi pula kepatuhan responden dalam melakukan pengobatan hipertensi secara teratur.

Menurut Thomas yang dikutip oleh (Nuraini, 2015) penghasilan merupakan salah satu faktor yang berperan dalam mewujudkan kondisi kesehatan seseorang atau masyarakat. Tinggi rendahnya penghasilan akan mempengaruhi daya beli seseorang terhadap barang-barang kebutuhan pokok diantaranya pemenuhan kebutuhan terhadap pelayanan kesehatan. Penghasilan adalah sesuatu yang harus didapatkan dari hasil bekerja terutama untuk menunjang kehidupannya dan keluarga. Orang yang berpenghasilan tinggi cenderung memiliki motivasi untuk mengunjungi fasilitas kesehatan sehingga akan semakin tinggi pula kesempatan untuk melakukan pengobatan (Notoatmodjo, 2012).

Hasil penelitian ini diperkuat penelitian yang dilakukan oleh (Kasjono et al., 2017) mengenai kepatuhan berobat pada penderita hipertensi, menunjukkan bahwa variabel pendapatan berhubungan dengan kepatuhan penderita hipertensi dengan penderita dalam melakukan pengobatan dengan menggunakan obat anti hipertensi. Hal ini juga didukung oleh penelitian (Wibawa, 2009) yang menunjukan hasil perhitungan dengan uji statistik Chi Square dengan nilai $\mathrm{p}=0,046$ yang menjelaskan bahwa terdapat hubungan antara penghasilan dengan kepatuhan berobat pada penderita Hipertensi.

Berbeda dengan hasil penelitian ini, dari penelitian (Riyadi et al., 2007) berdasarkan hasil analisis bivariat menunjukan bahwa tidak ada hubungan yang signifikan antara penghasilan dengan kepatuhan dalam menjalani pengobatan hipertensi dengan nilai $\mathrm{p}=0,908$. Hal ini dikarenakan dalam penelitian yang dilakukan oleh Tisna (2019) ditemukan tidak ada perbedaan kepatuhan dalam berobat antara responden yang berpenghasilan tinggi maupun kurang. 
JOURNAL OF PUBLIC HEALTH INOVATION

VOL. 2 No. 01, DESEMBER 2021

DOI: $10.34305 / j p h i . v 2 i 1.330$
Ciptaan disebarluaskan di bawah

Lisensi Creative Commons

Atribusi-NonKomersial-BerbagiSerupa 4.0
4. Korelasi Jarak Rumah Responden ke Puskesmas Dengan Kepatuhan Dalam Melakukan Pengobatan Hipertensi Secara Teratur

Berdasarkan hasil analisis bivariat dengan melakukan uji korelasi Rank Spearman dengan nilai $\mathrm{p}=0,010$ atau $\mathrm{p}<$ 0,05 maka keduanya dinyatakan memiliki hubungan. Untuk koefisien korelasinya didapatkan nilai positif 0,156 baik untuk jarak rumah responden ke Puskesmas maupun kepatuhan dalam melakukan pengobatan hipertensi secara teratur yang berarti korelasinya sangat lemah. Sehingga dapat disimpulkan bahwa semakin jauh jarak rumah responden ke fasilitas pelayanan Kesehatan/ Puskesmas maka semakin rendah pula kepatuhan responden dalam melakukan pengobatan hipertensi secara teratur.

Keterjangkauan akses ke pelayanan kesehatan adalah mudah atau sulitnya seseorang untuk mencapai tempat pelayanan kesehatan. (Niven, 2012) menyatakan bahwa salah satu faktor yang mempengaruhi kepatuhan berobat adalah faktor yang mendukung (enabling factor), yang terdiri atas tersedianya fasilitas kesehatan, kemudahan untuk menjangkau sarana kesehatan serta keadaan sosial ekonomi dan budaya. Rendahnya penggunaan fasilitas kesehatan seperti Puskesmas, rumah sakit dan sebagainya, seringkali kesalahan atau penyebabnya dilemparkan pada faktor akses ke pelayanan kesehatan (baik itu akses tempuh dan jarak ke fasilitas kesehatan). Keterjangkauan akses yang dimaksud dalam penelitian ini dilihat dari segi jarak, waktu tempuh dan kemudahan transportasi untuk mencapai pelayanan kesehatan. Semakin jauh jarak rumah pasien dari tempat pelayanan kesehatan dan sulitnya transportasi maka, akan berhubungan dengan kepatuhan berobat

Hasil penelitian ini diperkuat penelitian yang dilakukan oleh (Ambaw et al., 2012) yang menunjukkan bahwa jarak serta akses menuju ke rumah sakit memiliki pengaruh terhadap kepatuhan pasien hipertensi. Dalam penelitian diketahui bahwa jarak adalah penghalang besar bagi kepatuhan terhadap pengobatan hipertensi. Hal ini juga diperkuat oleh penelitian Salam dan (Wibawa, 2009) yang menunjukan bahwa ada hubungan yang bermakna antara jarak rumah dengan rumah sakit dengan kepatuhan melakukan pengobatan hipertensi dengan nilai $\mathrm{p}=0,0321$ dan OR $=3,262$. Analisis Multivariat Nya juga menunjukan bahwa ada hubungan yang bermakna antara jarak rumah dengan 
JOURNAL OF PUBLIC HEALTH INOVATION

VOL. 2 NO. 01, DESEMBER 2021

DOI: $10.34305 / j p h i . v 2 i 1.330$
Ciptaan disebarluaskan di bawah

Lisensi Creative Commons

Atribusi-NonKomersial-BerbagiSerupa 4.0 kepatuhan melakukan pengobatan hipertensi dengan nilai $\mathrm{p}=0,012$ dan $\mathrm{OR}=$ 5,210 .

Hasil penelitian ini tidak sejalan dengan penelitian yang dilakukan oleh (Anggara \& Prayitno, 2013) yang menyatakan tidak ada hubungan antara keterjangkauan pelayanan kesehatan dengan kepatuhan berobat hipertensi di Puskesmas $(p=0,063)$. Hal ini dikarenakan responden yang mudah menjangkau tempat pelayanan kesehatan dan patuh berobat hanya 3 orang $(20 \%)$ sedangkan yang tidak mudah menjangkau tempat pelayanan kesehatan namun patuh berobat sebanyak 52 orang $(45,2 \%)$. Sehingga dapat dikatakan orang yang tidak mudah menjangkau tempat pelayanan kesehatan justru lebih patuh dibandingkan dengan orang yang mudah menjangkau tempat pelayanan Kesehatan.

\section{Kesimpulan}

Berdasarkan hasil analisis dalam penelitian ini dapat disimpulkan bahwa:

1. Distribusi perilaku kepatuhan responden dalam melakukan pengobatan hipertensi secara teratur di Wilayah Kerja UPTD Puskesmas Hantara Kabupaten Kuningan tahun 2020 didapatkan hasil sebanyak 109 orang $(39,9 \%)$ diantaranya memiliki perilaku tidak patuh dalam melakukan pengobatan hipertensi secara teratur, sedangkan 164 orang $(60,1 \%)$ lainnya memiliki perilaku patuh dalam melakukan pengobatan hipertensi secara teratur.

2. Ada hubungan yang bermakna antara tingkat pengetahuan dengan kepatuhan dalam melakukan pengobatan hipertensi secara teratur di Wilayah Kerja UPTD Puskesmas Hantara Kabupaten Kuningan tahun 2020, hasil uji korelasi Rank Spearman dengan nilai $\mathrm{p}=0,000$ atau $\mathrm{p}<0,05$ dan nilai Correlation Coefficient sebesar 0,216 (lemah).

3. Ada hubungan yang bermakna antara tingkat Pendidikan dengan kepatuhan dalam melakukan pengobatan hipertensi secara teratur di Wilayah Kerja UPTD Puskesmas Hantara Kabupaten Kuningan tahun 2020,

4. Hasil uji korelasi Rank Spearman dengan nilai $\mathrm{p}=0,001$ atau $\mathrm{p}<0,05$ dan nilai Correlation Coefficient sebesar 0,206 (lemah).

5. Ada hubungan yang bermakna antara penghasilan dengan kepatuhan dalam melakukan pengobatan hipertensi secara teratur di Wilayah Kerja UPTD 
JOURNAL OF PUBLIC HEALTH INOVATION

VOL. 2 No. 01, DESEMBER 2021

DOI: $10.34305 / j p h i . v 2 i 1.330$
Ciptaan disebarluaskan di bawah

Lisensi Creative Commons

Atribusi-NonKomersial-BerbagiSerupa 4.0
Puskesmas Hantara Kabupaten

Kuningan tahun 2020, hasil uji korelasi

Rank Spearman dengan nilai $\mathrm{p}=0,037$ atau $\mathrm{p}<0,05$ dan nilai Correlation Coefficient sebesar 0,126 (sangat lemah).

6. Ada hubungan yang bermakna antara jarak rumah responden ke Puskesmas dengan kepatuhan dalam melakukan pengobatan hipertensi secara teratur di Wilayah Kerja UPTD Puskesmas Hantara Kabupaten Kuningan tahun 2020, hasil uji korelasi Rank Spearman dengan nilai $\mathrm{p}=0,010$ atau $\mathrm{p}<0,05$ dan nilai Correlation Coefficient sebesar 0,156 (sangat lemah).

\section{Saran}

1. Diharapkan penderita hipertensi agar teratur melakukan kontrol tekanan darah sesuai dengan anjuran dokter sehingga dapat meminimalisir kemungkinan komplikasi yang dapat terjadi.

2. Bagi keluarga/ kerabat terdekat penderita hipertensi diharapkan berperan aktif untuk selalu memberikan motivasi dan dukungan kepada anggota keluarga yang menderita hipertensi agar selalu rutin minum obat dan senantiasa patuh dalam melakukan pengobatan ke tempat-tempat pelayanan kesehatan.

3. Memberikan penyuluhan kesehatan kepada penderita hipertensi rawat jalan di Puskesmas Hantara dan pendidikan kesehatan tersebut sebaiknya tidak hanya diberikan kepada penderita hipertensi saja, namun juga kepada keluarga dan orang terdekat penderita hipertensi agar dapat ikut serta mengingatkan dan memberikan motivasi pada penderita hipertensi.

\section{Daftar Pustaka}

Ambaw, A. D., Alemie, G. A., W/Yohannes, S. M., \& Mengesha, Z. B. (2012). Adherence To Antihypertensive Treatment And Associated Factors Among Patients On Follow Up At University Of Gondar Hospital, Northwest Ethiopia. BMC Public Health, 12, 282. Https://Doi.Org/10.1186/1471-2458$12-282$

Amran, Y., Febrianti, F., \& Irawanti, L. (2010). Pengaruh Tambahan Asupan Kalium Dari Diet Terhadap Penurunan Hipertensi Sistolik Tingkat Sedang Pada Lanjut Usia. Kesmas: Jurnal Kesehatan Masyarakat Nasional (National Public Health Journal), 5(3), 125-130.

Anggara, F. H. D., \& Prayitno, N. (2013). Faktor-Faktor Yang Berhubungan Dengan Tekanan Darah Di Puskesmas Telaga Murni, Cikarang Barat Tahun 2012. Jurnal Ilmiah Kesehatan, 5(1), 
JOURNAL OF PUBLIC HEALTH INOVATION

VOL. 2 NO. 01, DESEMBER 2021

DOI: $10.34305 /$ jphi.v2i1.330
Ciptaan disebarluaskan di bawah

Lisensi Creative Commons

Atribusi-NonKomersial-BerbagiSerupa 4.0
$20-25$.

Aris, S. (2007). Mayo Clinic Hipertensi, Mengatasi Tekanan Darah Tinggi. Jakarta: PT Intisari Mediatama.

BPS Kabupaten Kuningan. (2019). Kuningan Dalam Angka. (Online).

Dinas Kesehatan Jawa Barat. (2020). Profil Kesehatan Jawa Barat Tahun 2019. Dinas Kesehatan Jawa Barat. Www.Diskes.Jabarprov.Go.Id

Dinas Kesehatan Kabupaten Kuningan. (2020). Profil Kesehatan Kuningan. Dinas Kesehatan Kabupaten Kuningan Jawa Barat.

Entianopa, M., Marisdayana, R., Andriani, L., \& Hendriani, V. (2017). Analisis Pelaksanaan Program Stbm Pilar Pertama Stop Buang Air Besar Sembarangan Di Desa Ampelu Kabupaten Batanghari. Jurnal Kesehatan Terpadu, 1(2). Https://Doi.Org/10.36002/Jkt.V1i2.26 7

Harahap, D. A., Aprilla, N., \& Muliati, O. (2019). Hubungan Pengetahuan Penderita Hipertensi Tentang Hipertensi Dengan Kepatuhan Minum Obat Antihipertensi Di Wilayah Kerja Puskesmas Kampa Tahun 2019. Jurnal Ners, 3(2), 97-102.

Jankowska-Polańska, B., Uchmanowicz, I., Dudek, K., \& Mazur, G. (2016). Relationship Between Patients' Knowledge And Medication Adherence Among Patients With Hypertension. Patient Preference And Adherence, 10, 2437-2447. Https://Doi.Org/10.2147/PPA.S1 1726 9
Kasjono, H. S., Widyantoro, W., \& Pujiyati, N. E. (2017). Model Pemberdayaan Masyarakat Dalam Melaksanakan 5 Pilar STBM Di Sorowajan Bantul. AKSIOLOGIYA: Jurnal Pengabdian Kepada Masyarakat, $\quad 1(2), \quad 142$. Https://Doi.Org/10.30651/Aks.V1i2.9 38

Niven, N. (2012). Psikologi Kesehatan: Pengantar Untuk Perawat Dan Tenaga Kesehatan Profesional Lain. Jakarta: $E G C$.

Notoatmodjo, S. (2012). Promosi Kesehatan Dan Perilaku Kesehatan. Rineka Cipta.

Notoatmodjo, S. (2014). Promosi Kesehatan Teori Dan Aplikasinya. Rineka Cipta.

Nugraha, B. (2018). Hubungan Tingkat Pengetahuan Pasien Dengan Kepatuhan Dalam Menjalankan Diit Hipertensi (Di Irna 6 RSUD Dr. Sayidiman Magetan). Stikes Insan Cendekia Medika Jombang.

Nuraini, B. (2015). Risk Factors Of Hypertension. Jurnal Majority, 4(5).

Pujiyanto, P. (2008). Faktor Sosio Ekonomi Yang Mempengaruhi Kepatuhan Minum Obat Antihipertensi. Kesmas: National Public Health Journal, 3(3), 139.Https://Doi.Org/10.21109/Kesmas .V3i3.228

Rachmawati, A. N., \& Ekarini, D. (2015). Pengaruh Relaksasi Progresif Terhadap Penurunan Tekanan Darah Pada Penderita Hipertensi Stage 1 Di Puskesmas Gondangrejo Karanganyar. 
JOURNAL OF PUBLIC HEALTH INOVATION

VOL. 2 NO. 01, DESEMBER 2021

DOI: $10.34305 /$ jphi.v2i1.330
Ciptaan disebarluaskan di bawah

Lisensi Creative Commons

Jurnal Kesehatan Kusuma Husada.

Rasajati, Q. P., Raharjo, B. B., \& Ningrum, D. N. A. (2015). Faktor-Faktor Yang Berhubungan Dengan Kepatuhan Pengobatan Pada Penderita Hipertensi Di Wilayah Kerja Puskesmas Kedungmundu Kota Semarang. Unnes Journal Of Public Health, 4(3).

Riskesdas. (2007). Badan Penelitian Dan Pengembangan Kesehatan.

Riskesdas. (2013). Riset Kesehatan Dasar. Balitbang Kemenkes Ri.

Riskesdas. (2018). Badan Penelitian Dan Pengembangan Kesehatan Kementerian RI Tahun 2018.

Riyadi, A., Wiyono, P., \& Budiningsari, R. D. (2007). Asupan Gizi Dan Status Gizi Sebagai Faktor Risiko Hipertensi Esensial Pada Lansia Di Puskesmas Curup Dan Perumnas Kabupaten Rejang Lebong Propinsi Bengkulu. Jurnal Gizi Klinik Indonesia, 4(1), 4351.

Suwarso, W. (2010). Analisis Faktor Yang Berhubungan Dengan Ketidakpatuhan Pasien Penderita Hipertensi Pasa Pasien Rawat Jalan Di RSU H. Adam Malik, Universitas Sumatera Utara, Medan.

Wibawa, R. A. (2009). Hubungan Antara Cara Bayar Dengan Kepatuhan Berobat Pada Pasien Hipertensi Rawat Jalan. 